\title{
Treatment of a neglected flexor digitorum profundus entrapment after closed reduction of both bone forearm fracture: A case report
}

\author{
Serdar Koluaçık, MD¹D, Özgür Yılmaz, MD²Đ, Okan Aslantürk, $M^{3} \mathbb{D}$ \\ ${ }^{1}$ Department of Orthopedics and Traumatology, Malatya Training and Research Hospital, Malatya, Turkey \\ ${ }^{2}$ Department of Orthopedics and Traumatology, Fethi Sekin City Hospital, Elazı ̆̆, Turkey \\ ${ }^{3}$ Department of Orthopedics and Traumatology, Inönü University Faculty of Medicine, Malatya, Turkey
}

Both bone forearm fracture (BBFF) is the most common fracture of pediatric population accounting for about $50 \%$ of all pediatric fractures. ${ }^{[1]}$ Most of these fractures treated with non-surgically with closed reduction and long arm casting under sedation in the emergency department or operating room. ${ }^{[2]}$ Surgical management is indicated, when adequate or stable reduction cannot be achieved. ${ }^{[2]}$ Excellent results have been reported in the literature both with non-surgical and surgical management. ${ }^{[1]}$ However, there are well-known complications of treatment of forearm fractures such as compartment syndrome, malunion, and neurovascular injury. ${ }^{[2]}$ Nerve and tendon entrapment in the fracture line after reduction are rarely reported complication of these fractures. ${ }^{[3-13]}$

Received: August 20, 2021

Accepted: September 26, 2021

Published online: November 19, 2021

Correspondence: Okan Aslantürk, MD. İnönü Üniversitesi Tıp Fakültesi Ortopedi ve Travmatoloji Anabilim Dalı, 44280 Malatya, Türkiye.

E-mail: okaslanturk@hotmail.com

Doi: $10.52312 /$ jdrs.2021.389

Citation: Koluaçık S, Yılmaz Ö, Aslantürk O. Treatment of a neglected flexor digitorum profundus entrapment after closed reduction of both bone forearm fracture: A case report. Jt Dis Relat Surg 2021;32(3):810-813.

(02021 All right reserved by the Turkish Joint Diseases Foundation

This is an open access article under the terms of the Creative Commons Attribution-NonCommercial License, which permits use, distribution and reproduction in any medium, provided the original work is properly cited and is not used for commercial purposes (http://creativecommons.org/licenses/by-nc/4.0/).

\section{ABSTRACT}

Flexor tendon entrapment (FTE) is a rare and usually lately diagnosed complication of pediatric forearm fractures. In this case report, we present a case of a neglected ring and little finger flexor digitorum profundus (FDP) entrapment after closed reduction of both bone forearm fracture and treated five years later due to late diagnosis. A 20-year-old man presented to outpatient clinic with flexion contracture of ring and little finger that occurred after both-bone forearm fracture treated with closed reduction and long arm cast five years ago. On his physical examination, flexion contracture of ring and index fingers was thought to be due to entrapment of tendons at the level of forearm and surgically released. Five years after surgical treatment for FTE, the patient had full range of motions at both fingers. He had no additional complaint. In conclusion, FTE is a rare complication after both bone forearm fractures. It should be kept in mind in the treatment of both bone forearm fractures. Surgical treatment of FTE in late cases is an effective procedure with excellent results.

Keywords: Forearm fracture, late diagnosis, pseudo-Volkmann, tendon entrapment.

In this article, we present treatment of flexor digitorum profundus (FDP) tendon entrapment of ring and little finger five years after closed reduction of BBFF.

\section{CASE REPORT}

A 20-year-old male patient presented to the outpatient clinic with inability to extend at ring and little finger of left hand. In his medical history, he had a BBFF treated with closed reduction and long arm casting five years ago. On his physical examination, the patient had lack of passive and active extension at proximal and distal interphalangeal joints of both ring and little fingers 

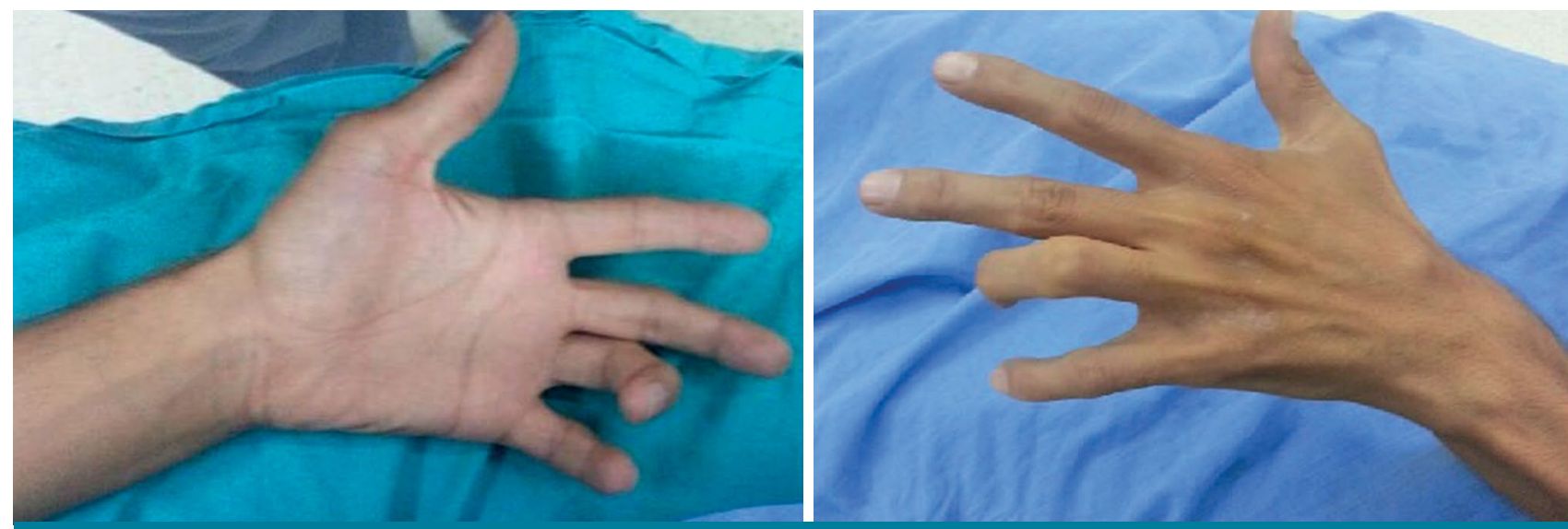

FIGURE 1. Flexion contracture of ring and small finger.

when wrist in the neutral position (Figure 1). The patient was able to extend both finger when the wrist was flexed. The patient reported failure of previous physical treatment. Surgical exploration was planned. The patient was informed about surgery and a written informed consent was obtained.

Under axillary block anesthesia, the patient was positioned in supine and the forearm was placed on hand table. A pneumatic tourniquet was placed proximal of arm. The extremity was exsanguinated with the Esmarch bandage and the tourniquet was inflated. Then, a volar ulnar incision was made from the wrist to the proximal forearm to identify the entrapment site. The FDP tendons of the ring and small finger were found to be entrapped in ulnar shaft (Figure 2). The tendons were liberalized and passive extension of both ring and little finger was achieved intraoperatively. Myotenolysis was performed for both tendons. After deflation of the tourniquet, meticulous hemostasis was achieved, and wound was closed in a standard fashion.

Postoperatively, the arm was placed into a dorsal long arm splint. Passive range of motion exercises were started one week after surgery. The splint was removed at six weeks after surgery. During five-year-follow-up, the patient had full extension and flexion at small and ring fingers (Figure 3).

\section{DISCUSSION}

Flexor tendon entrapment, also named as pseudo-Volkmann contracture, is a rarely seen complication of forearm fractures. Patients with FTE are unable to extend affected fingers in wrist extension; however, when the wrist in flexion position, they are able to extend affected fingers. The FTE can be mixed with Volkmann ischemic contractures. However, in FTE patients, there is no
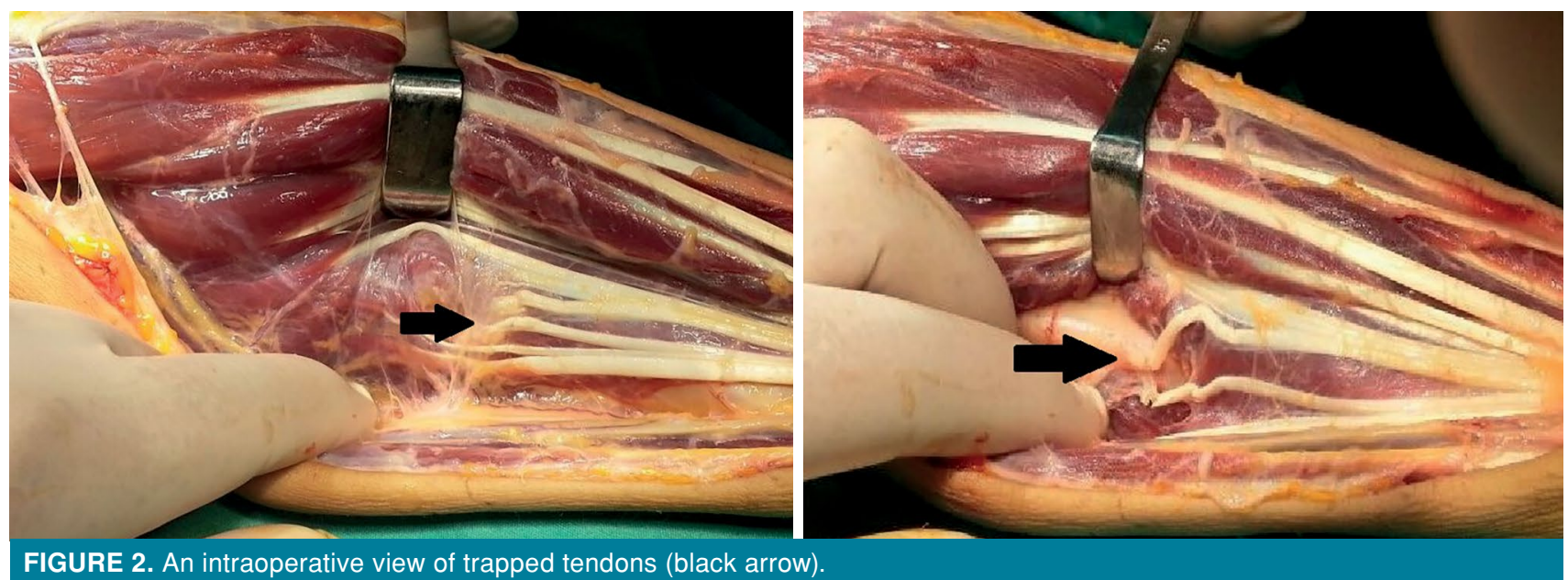

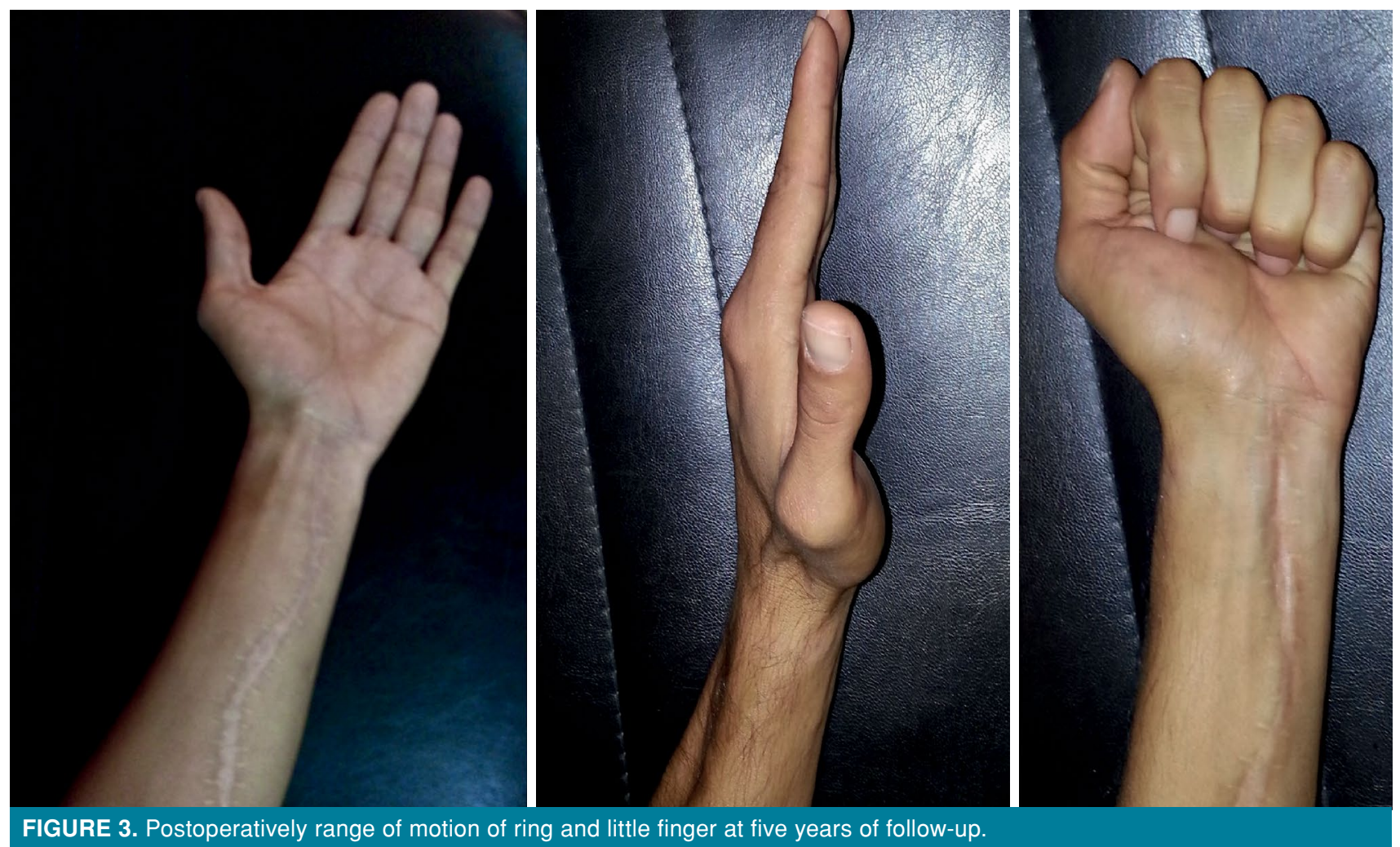

FIGURE 3. Postoperatively range of motion of ring and little finger at five years of follow-up.

clinical ischemic findings and no muscle ischemia during the surgical treatment..$^{[1]}$ Our patient had entrapment of FDP tendon of both ring and little fingers after closed reduction of BBFF. To the best of our knowledge, this is the first case reported from Turkey. ${ }^{[14]}$

Review of the literature reveals 31 cases (both children and adults) of FTE after forearm fractures. ${ }^{[2-9,12,13]}$ In 13 of previous 31 cases, only one finger was affected, while two or more fingers were affected in 18 cases. ${ }^{[2-9,12,13]}$ The average age of patients is 11.6 years ranging from 4 to $28 .^{[2-9]}$ Flexor tendon entrapment was most commonly reported after closed reduction of BBFF. ${ }^{[7]}$ However, there are also cases of FTE reported following isolated ulnar or radial factures and surgical treatment. ${ }^{[3,6-9,12]}$ In the literature, the initial treatment was closed reduction and casting in 20 cases, open reduction and internal or intramedullary fixation in five cases, closed reduction and intramedullary or percutaneous fixation in three cases, and unknown in three patients..$^{[2-9,12,13]}$ In our patient, the underlying cause of the entrapment was closed reduction of BBFF.

For early diagnosis of FTE, careful examination of fingers should be performed after closed reduction or surgical treatment of forearm fractures. Thione et al. $^{[6]}$ and Page et al. ${ }^{[13]}$ also reported FTE in callus; therefore, physician should be careful during follow-up, if there is no sign of FTE in the early period of treatment. In case of a lack of careful examination, diagnosis of FTE may be delayed until cast removal or even years later. ${ }^{[2-9,13]}$ In case of early diagnosis of FTE, it can be successfully treated with conservative techniques. ${ }^{[8,12]}$ Deeney et al. ${ }^{[8]}$ reported 16 years of delay in diagnosis of middle and ring ringer FDP entrapment after closed reduction for BBFF. In our case, the patient presented five years after the initial treatment.

When the FTE is diagnosed lately, surgical treatment should be performed. Twenty-eight of 31 previously reported in the literature were treated surgically. ${ }^{[2-9]}$ Twenty-six of 28 had full recovery, only two patients had slight tenodesis. ${ }^{[2-9]}$ Surgical interventions include open release, release and lengthening, myotenolysis, tendon transfer, and tenodesis. ${ }^{[2-9]}$ Our patient also fully recovered after myotenolysis and had no problem at five years after surgical treatment.

In conclusion, FTE is a rare, but important and treatable complication of forearm fractures. It can be 
misdiagnosed as the Volkmann ischemic contracture; however, the lack of ischemic findings clinically and surgically may help to rule out Volkmann contracture. For early diagnosis, the finger range of motions should be checked immediately after reduction. When the FTE is diagnosed early, non-surgical treatments could be utilized for tendon release. If there is a delayed diagnosis, surgical intervention should be performed. Surgical treatments have excellent results in most of the cases.

\section{Declaration of conflicting interests}

The authors declared no conflicts of interest with respect to the authorship and/or publication of this article.

\section{Funding}

The authors received no financial support for the research and/or authorship of this article.

\section{REFERENCES}

1. Jones K, Weiner DS. The management of forearm fractures in children: A plea for conservatism. J Pediatr Orthop 1999;19:811-5.

2. Fernandez ML, Segal LS. Entrapment of the flexor digitorum profundus following paediatric forearm fractures. Acta Orthop Belg 2007;73:780-4.

3. Akita S, Kawai H. Entrapment of the flexor digitorum superficials in the radius fracture site. J Hand Surg Am 2005;30:308-11.

4. Song DJ, Kennebrew GJ Jr, Jex JW. Isolated ring finger flexor digitorum profundus entrapment after closed reduction and intramedullary fixation of both-bone forearm fracture. Orthopedics 2012;35:e1283-5.
5. Brogan K, Nicol S. Flexor digitorum profundus entrapment in paediatric forearm fractures. J Surg Case Rep 2014;2014:rju038.

6. Thione A, Cavadas PC, Rubi CG. Entrapment of the flexor digitorum profundus in the callus after a closed distal radial fracture. Plast Reconstr Surg Glob Open 2016;4:e687.

7. Geissler J, Westberg J, Stevanovic M. Pseudo-Volkmann contracture: A case report and review of the current literature. J Am Acad Orthop Surg Glob Res Rev 2018;2:e031.

8. Deeney VF, Kaye JJ, Geary SP, Cole WG. Pseudo-Volkmann's contracture due to tethering of flexor digitorum profundus to fractures of the ulna in children. J Pediatr Orthop 1998;18:437-40.

9. Jeffery CC. Contracture of fingers due to fixation of the flexor profundus digitorum to the ulna. Hand 1976;8:32-5.

10. Proubasta IR, De Sena L, Cáceres EP. Entrapment of the median nerve in a greenstick forearm fracture. A case report and review of the literature. Bull Hosp Jt Dis 1999;58:220-3.

11. Hirasawa H, Sakai A, Toba N, Kamiuttanai M, Nakamura $\mathrm{T}$, Tanaka K. Bony entrapment of ulnar nerve after closed forearm fracture: A case report. J Orthop Surg (Hong Kong) 2004;12:122-5.

12. Toga A, Balaji A, Matsumoto T, Fujimaru A, Murakami H, Katoh S. Flexor tendon entrapment of the index finger after Monteggia fracture in a pediatric patient. Orthop Res Rev 2020;12:189-93.

13. Page F, Yacomel T, Ting J, Dimitriou R, Oestreich K. Tenodesis effect mimicked by flexor tendon entrapment in a paediatric midshaft forearm fracture: A case report and review of the literature. SN Comprehensive Clinical Medicine 2020;2:1-8.

14. Atik OŞ. What are the expectations of an editor from a scientific article? Jt Dis Relat Surg 2020;31:597-8. 